\title{
Ergonomics in Laparoscopic Surgery
}

\author{
Francisco M. Sánchez-Margallo and \\ Juan A. Sánchez-Margallo \\ Additional information is available at the end of the chapter
}

http://dx.doi.org/10.5772/66170

\begin{abstract}
Despite the many advantages for patients, laparoscopic surgery entails certain ergonomic inconveniences for surgeons, which may result in decreasing the surgeons' performance and musculoskeletal disorders. In this chapter, the current status of ergonomics in laparoscopy, laparoendoscopic single-site surgery (LESS), and robotassisted surgery will be reviewed. Ergonomic guidelines for laparoscopic surgical practice and methods for ergonomic assessment in surgery will be described. Results will be based on the scientific literature and our experience. Results showed that the surgeon's posture during laparoscopic surgery is mainly affected by the static body postures, the height of the operating table, the design of the surgical instruments, the position of the main screen, and the use of foot pedals. Ergonomics during the laparoscopic surgical practice is related to the level of experience. Better ergonomic conditions entail an improvement in task performance. Laparoscopic instruments with axial handle lead to a more ergonomic posture for the wrist compared to a ring handle. LESS is physically more demanding than conventional and hybrid approaches, requiring greater level of muscular activity in the back and arm muscles, but better wrist position compared with traditional laparoscopy. Physical and cognitive ergonomics with robotic assistance were significantly less challenging when compared to conventional laparoscopic surgery.
\end{abstract}

Keywords: Ergonomics, laparoscopic surgery, laparoendoscopic single-site surgery, robotic instrument, electromyography, motion capture 


\section{Introduction}

Despite the many advantages for patients, laparoscopic surgery entails certain ergonomic inconveniences for surgeons, namely, loss of freedom during surgical maneuvers, deriving in an increased incidence of static postures, and adoption and maintenance of forced body postures for long periods of time. Since laparoscopic surgery became more advanced, operating time expanded and, in proportion, so did the levels of mental and physical stress imposed on the surgical team [1]. The combination of these factors with inadequate ergonomic design of surgical instruments may result in decreasing the surgeons' performance and accuracy, as well as the incidence of physical fatigue and musculoskeletal disorders.

The main technical limitations of laparoscopic surgery come from the technical modifications with regard to the open approach. Visual displays are located apart from the surgical field, affecting hand-eye coordination. Furthermore, bidimensional vision causes a confusing loss of depth perception. Specific instruments and fixed access ports limit movements and tactile feedback, worsening surgical performance and demanding greater muscular activity [2]. Design of laparoscopic tools implies a high degree of complexity, requiring manual skills and complementary new knowledge of how to use them. Design of surgical instruments and medical devices, as well as specific location of the monitor, operating table, foot pedals, and other surgical equipment determine to a large extent surgeons' postures while performing surgical procedures and the organization of the surgical team.

The introduction of laparoendoscopic single-site surgery (LESS) has led to a reduction of the number and size of incisions, thus providing aesthetical and emotional improvements to the patients. Positive results have been reported for this surgical approach with regard to postoperative outcomes, recovery time, length of hospital stay, and related costs [3]. LESS inherits the constraints of conventional laparoscopic surgery, adding new technical challenges. Working through a single port implies a defective triangulation, even more lack of coordination, external and internal instrument clashing, forced hands approximation with restrained manipulation, narrowing of the operative field, and possible pneumoperitoneum leakage [4]. Therefore, the use of LESS approach leads to a greater physical and mental workload for the surgeons $[5,6]$.

Robotic surgery is an increasingly expanding technology that uses human-machine interfaces providing solutions to laparoscopic constraints through enhanced dexterity, maneuverability, stability, and accuracy. Several studies reported lower complication rates and blood loss than conventional laparoscopic surgery [7]. This technology has been also integrated with LESS, and even more complex procedures by means of flexible access devices [8]. The main limitations of robotic surgery are high expenses and maintenance costs, difficulty to use it in lowvolume or low-income centers, required experience from the surgical team, and instruments replacement [9].

The term ergonomics can be defined as the scientific study of humans at labor. The main objective of this field is to adapt environments to workers, improving equipment, workplaces, productivity, and training [10]. In this respect, ergonomics applied to laparoscopic surgery is focused on instruments' design and ergonomic assessment, surgeons' posture and workload 
analysis, surgical environment, and visual displays development [11, 12]. The main objective of this chapter is to review and analyze the ergonomic conditions during laparoscopic surgery and novel minimally invasive surgical approaches such as LESS and robotic surgery, as well as to establish ergonomic guidelines for laparoscopic surgical practice. In order to reach more representative information, studies published after 2010 and with over 20 subjects will be taken into account, excluding the review articles. The content of this chapter will be organized in three main sections: general ergonomic aspects in laparoscopic surgery, methods and technologies for ergonomic assessment in surgery, and ergonomics in minimally invasive surgical approaches.

\section{General aspects}

In laparoscopic surgery there are some primary ergonomic risk factors for the surgeon such as the body posture, the organization of the work space in the operating room (OR), and the design of the surgical tools.

\subsection{Body posture}

Laparoscopic surgery has changed the way surgeons interact in the operating field, what is revealed by a change in their posture and movements mainly of the upper limbs. In laparoscopic surgery dexterity is limited due to the fixed access port position, determining the angle of the instruments and instruments motion. Degrees of freedom are restricted from 36 in open surgery to 4 in laparoscopic surgery. This limited range of action leads to surgeons to acquire static, forced, and awkward long-term postures. The primary risk factor for the appearing of musculoskeletal disorders is body deviation from the neutral position. The ideal position for the laparoscopic surgeon is characterized by the arms slightly abducted, retroverted, and rotated inward at the shoulder level; the elbow should be bent at a $90-120^{\circ}$ angle; the hands should grasp the instruments with the wrist slightly extended and with the distal interphalangeal joints almost extended, and the metacarpophalangeal and proximal interphalangeal joints flexed at $30-50^{\circ}$; fingers should be abducted and the thumb should be opposed to the index finger [13, 14]. Surgical team and equipment location in relation to the patient also must be considered. Likewise, lower body position can be non-ergonomic, provoking physical stress. Surgeons usually perform long procedures standing with a potential loss of stability and limited possibilities to change their body weight, especially when foot pedals are used [15].

\subsection{Working environment}

The workplace organization means that every individual member of the surgical team has appropriate space and access to all equipment. A lack of balance between the surgical staff and OR components can lead to work overloads and injuries. The advances in the field of laparoscopy are reflected in the development of optics with higher resolution and improved operational instruments. However, this progress has not always been accompanied by an ergonomic upgrade, which would alleviate some of the problems experienced by laparoscopic 
surgeons. Besides, some considerations have to be taken into account when using the laparoscopic equipment before and during surgical procedures.

\subsubsection{The monitor}

The visual information from the surgical scenario is provided by a monitor, which should be adjusted prior to the surgery to avoid undesirable postures for a long period of time. In the horizontal plane, the monitor should be straight ahead of the surgeon and in line with the forearm-instrument motor axis. In the sagittal plain, it should be positioned lower than the surgeon's eye level to avoid neck extension. The most comfortable viewing direction is approximately $15^{\circ}$ downward. Viewing distance is highly dependent on monitor size. It should be far enough to avoid extensive accommodation of the eyes and contraction by the extraocular muscles, and close enough to avoid staring and loss of detail [16, 17]. To accomplish precision tasks, the use of an additional monitor near the operative field is recommended, as it improves hand-eye coordination $[12,17]$.

\subsubsection{Operating table}

The operating table must be adapted to the surgeon's height and position (standing or sitting). If the operating table is placed too high, muscles apply considerably more contraction force in order to raise and hold the shoulders as well as the elbows. If that position is maintained for a period of time it leads quickly to shoulder muscles fatigue. The table's height should be adjusted in such a way that laparoscopic instrument handles are slightly below the level of the surgeon's elbows. The proper table location keeps shoulders down, and the angle between the lower and upper arm is between $90^{\circ}$ and $120^{\circ}$ when performing manual work $[18,19]$. Lifts can be used in case the table cannot be lowered to a certain height.

\subsubsection{Foot pedals}

Foot pedals are commonly used during laparoscopic surgery to activate instruments such as electrocauterization, ultrasonic shears, bipolar device, or other tissue welding/dividing instruments. They are often poorly positioned and could demand awkward and unnatural postures. Their main problems are the lack of visual control, unbalanced position of the surgeon, and use of too many pedals during laparoscopic surgery. A possible solution could be replacing them with hand controls when possible. Pedals should be placed near the foot and aligned in the same direction as the instruments, toward the target quadrant and laparoscopic monitor. This allows surgeons to activate the pedal without twisting their body or leg. A pedal with a built-in foot rest is preferable [20].

\subsubsection{Surgical instruments}

The performance of laparoscopic procedures and the position of surgeon's arms, hands, and fingers are highly dependent on the design of surgical instruments, mainly on the shape of the handle and the tool length. The non-ergonomic designs of handles that are not adapted to the shape and size of the surgeon's hand may lead to discomfort, paresthesias of the digital nerves 
and muscle fatigue [13]. Surgical instruments should enable surgeons to minimize the wrist flexion and rotation and ulnar deviation, keeping both arms at the sides of their body, and avoiding pressure points on their hands and fingers. Design of instrument handle should be according to the task to be performed, pistol-type handle for tasks that required force and precision-type handle for tasks that require precision [20].

\section{Methods for ergonomic assessment}

\subsection{Body posture}

The analysis of the interaction between the surgeon and surgical environment is a determinant factor to evaluate the ergonomic suitability of the working environment and provides crucial information to establish its basic design features. Traditional methods to assess surgeon's postures associated with a specific surgical activity have been based on observation techniques (photogrammetry) by observing the subject directly or using a recorded video [21, 22]. However, assessment methods have evolved and currently it is possible to perform and ergonomic analysis in the OR and using more automated technology. In this section, different methods of ergonomic assessment will be described based on kinematic analysis, muscle activity, or mental stress.
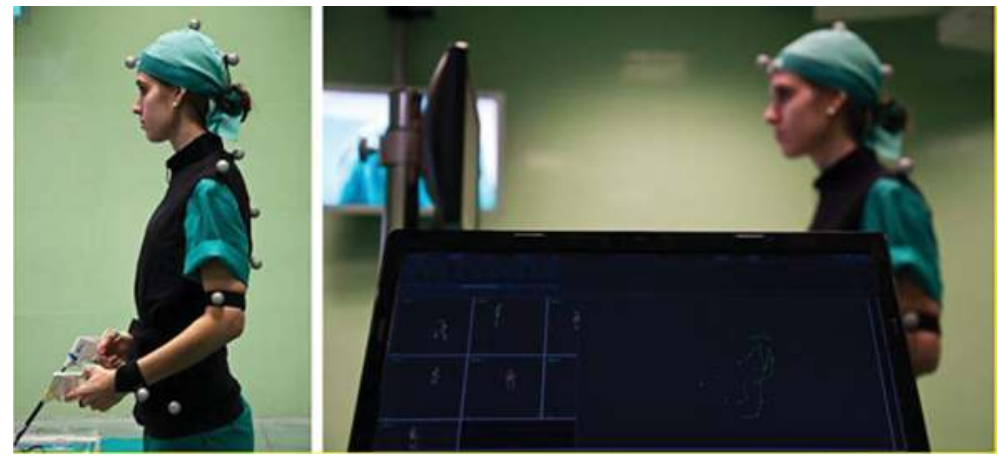

Figure 1. Motion tracking system based on retro-reflective markers. Artificial markers are placed on the targeted segments of the surgeon's body $(l e f t)$. A software application computes the kinematics variables during the task execution (right).

\subsubsection{D motion tracking}

These measurement systems quantify human movements by means of positional data obtained from artificial markers or sensors placed on the subject's body. Optical tracking techniques are based on color or retro-reflective markers that are identified at the three-dimensional space by a set of cameras [23] around the working space (Figure 1). However, these markers may have some occlusion problems in crowded spaces such as the OR, mainly because of the surgical 
staff and equipment. Another technology for motion tracking is the use of inertial sensors to record in real time the different body segments for subsequent kinematic analysis (Figure 2). These inertial measurement units are not affected by visual occlusions, and thus are appropriate for working environments as the OR.

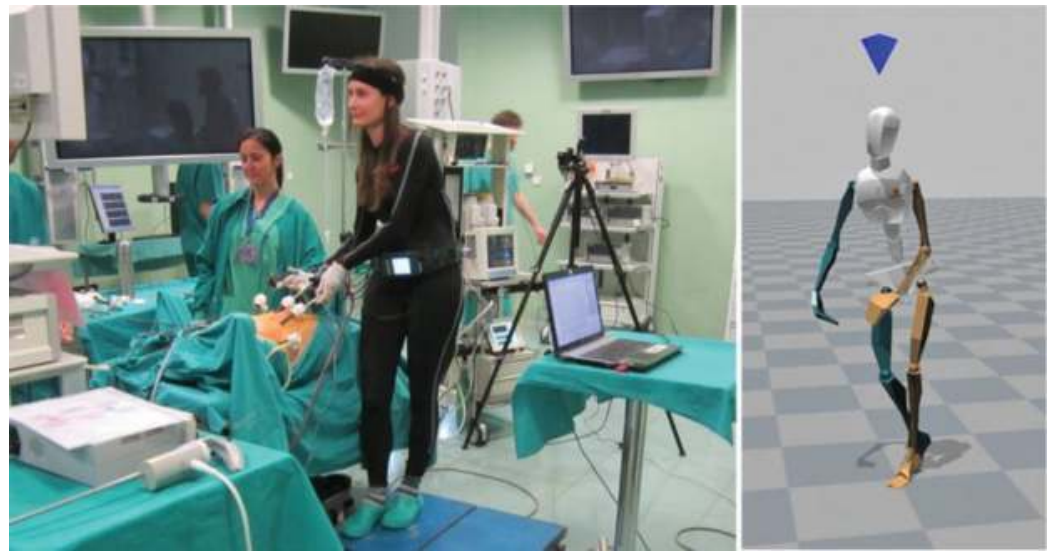

Figure 2. Motion tracking system based on inertial sensors embedded in an elastic suit (left). A biomechanical model of the subject is created in real time (right).

A set of kinematics variables such as translational and rotational positions, velocities, and accelerations can be computed using the recorded positional data of the subject. Afterwards, the surgeon's posture can be analyzed with standard evaluation techniques such as Rapid Upper Limb Assessment (RULA) method or Ovako Working Analysis System (OWAS). Youssef et al. [24] compared variations in the surgeon's standing position during a virtual reality-simulated laparoscopic cholecystectomy using RULA score. They obtained better ergonomic posture for the between-standing technique, regardless of whether one- or twohanded technique. 3D kinematic analysis was used to differentiate joint variability between conventional laparoscopy and LESS [21], evaluating the influence of the upper body to the head stabilization.
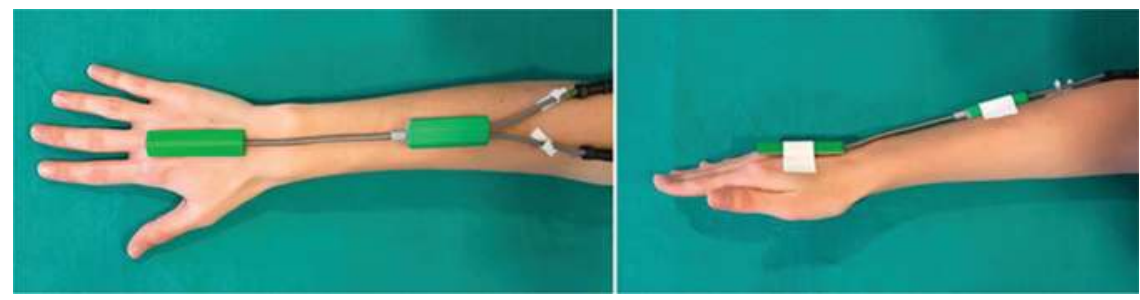

Figure 3. Placement of an electrogoniometer on the hand to record the wrist flexion-extension and radial-ulnar deviation. 


\subsubsection{Electrogoniometers}

Electrogoniometers are devices whose measurement signals (typically electrical voltages) are related directly to flexion-extension or rotation between body segments. These devices should be precalibrated to relate the measured voltage with the angles described by the analyzed joint (Figure 3). However, this measurement technology may be difficult to use for certain body segments. Besides, the need to be attached to the body segments and the use of wires for power supply make these devices a cumbersome solution to be used during laparoscopic practice.

\subsubsection{Data gloves}

Surgical tasks and instruments directly affect the surgeon's wrist and hand position. Data gloves allow for recording movements of the fingers and wrist by means of electromechanical technology or conductive sensors. In the clinical field, these devices have been used in conjunction with virtual reality systems for rehabilitation purposes [25] and surgical planning applications [26]. Recently, this technology has been used to analyze the surgeon's hand movements while using different surgical instruments during laparoscopic practice $[5,8,11,27]$ (Figure 4).

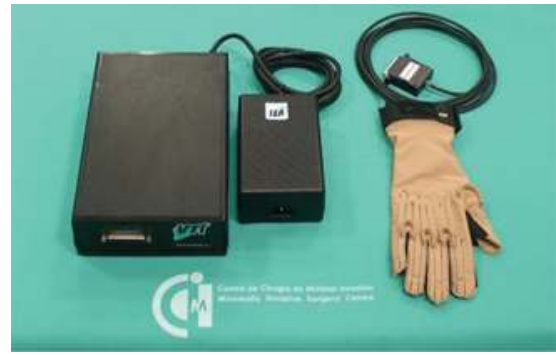

Figure 4. Motion capture data glove CyberGlove ${ }^{\circledR}$ (CyberGlove Systems, San José, CA, USA). This device consists of a series of conductive sensors with resistance flows sensitive to flexion variations.

\subsection{Electromyography}

Electromyography (EMG) measures the electrical signal associated with the activation of the muscle. This technique allows us to assess the electrical activity of a muscle group during the performance of a task. For data acquisition, electrodes should be placed following standard recommendations, as the surface EMG for noninvasive assessment of muscles (SENIAM) project [28], to ensure the acquisition of EMG signals and reduce potential artifacts.

Several metrics of muscle activity during the execution of a certain task can be computed by analyzing the EMG signal such as the percentage of the maximal voluntary contraction (MVC) [29], the amplitude probability distribution function (APDF) [30], or the muscle fatigue [6]. EMG has been an extended ergonomic assessment method in laparoscopic surgery to analyze 
the surgeon's postural muscle activity $[5,11]$, the use of different surgical instruments, and instrument handles [27, 31] (Figure 5).

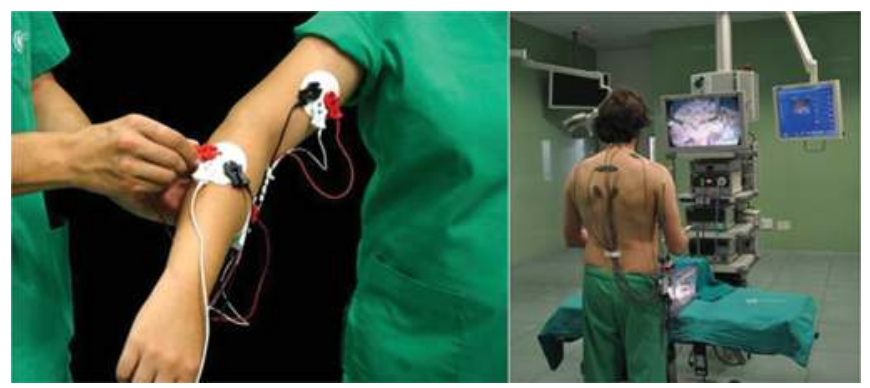

Figure 5. Placement of the EMG electrodes on the right biceps brachii and forearm extensors (left). Use of the surface EMG to analyze the muscle activity of the upper body during laparoscopic practice (right).

\subsection{Force platforms}

Force platforms (single or multiple) are used to analyze the body balance during static or dynamic situations. These systems provide information about ground's reaction force against the force exerted by the subject's legs while supporting the body weight. Fan et al. [32] presented an alternative position to conventional flank position in retroperitoneoscopic urological practice. Body balance was assessed during simulated surgical tasks using two separate force plates (Wii Fit balance boards, Nintendo Inc.). They concluded that relative loading between feet was more balanced using the purposed posture.

\subsection{Mental workload}

Apart from the physical effort, psychological burden of surgeons performing laparoscopic procedures is reported higher in comparison to open surgical techniques [15]. For mental workload assessment, subjective techniques are the most extended methods. The National Aeronautics and Space Administration Task Load Index (NASA-TLX) evaluates six domains: mental demand, physical demand, temporal demand, effort, performance, and frustration during each task execution. A surgery-specific version of the NASA-TLX called SURG-TLX was presented and validated in 2011 [33]. Apart from the physical, mental, and temporal demand, this index assessed the task complexity, the situational stress, and distractions. Studies reported LESS is significantly more demanding than the conventional approach [34]. Training has been proved to improve both task performance and workload in laparoscopic practice [35].

\subsection{Questionnaires}

Questionnaires are another assessment tool that focuses on gathering information from a population of surgeons. Taking into account studies with at least 100 respondents, a survey 
to laparoscopic urologists in China concluded that most of them were not aware of the ergonomic guidelines for the OR [36]. Shoulder, neck, back, and hand pain and stiffness were reported as the main physical symptoms during laparoscopic procedures [36, 37]. The surgeon's height, glove size, age, gender, type of instrument, foot pedals, and height of the operating table have been identified as important factors for increasing the musculoskeletal pain symptoms [38-41]. The shape of the laparoscopic instrument handle was identified as the main element that needed to be improved [40].

\section{Ergonomics in laparoscopic surgery}

A summary of the results from the scientific literature regarding ergonomics in laparoscopic surgery are presented in Table 1 .

\begin{tabular}{|c|c|c|c|c|}
\hline Study & $N$ & Task & Assessment method & Results \\
\hline [12] & 24 novices & $\begin{array}{l}\text { Peg transfer with different } \\
\text { monitor conditions }\end{array}$ & NASA-TLX & $\begin{array}{l}\text { There are no differences among } \\
\text { monitor positions in terms of } \\
\text { perceived workload }\end{array}$ \\
\hline [16] & 20 novices & $\begin{array}{l}\text { Suturing on simulator with } \\
\text { ergonomic (G1) and normal } \\
\text { (G2) settings }\end{array}$ & $\begin{array}{l}\text { Photogrammetry: } \\
\text { Neck, shoulder, elbow, } \\
\text { and wrist }\end{array}$ & $\begin{array}{l}\text { Optimal ergonomic setting leads to } \\
\text { better task performance }\end{array}$ \\
\hline [24] & 32 & $\begin{array}{l}\text { Cholecystectomy on virtual } \\
\text { simulator with variations in } \\
\text { standing position and hand } \\
\text { technique }\end{array}$ & $\begin{array}{l}\text { RULA } \\
\text { NASA-TLX }\end{array}$ & $\begin{array}{l}\text { Better ergonomic posture for the } \\
\text { between-standing technique } \\
{[30]}\end{array}$ \\
\hline [30] & 25 & $\begin{array}{l}\text { Open, laparoscopic, and } \\
\text { endovascular procedures }\end{array}$ & $\begin{array}{l}\text { EMG: Back, neck, and } \\
\text { shoulder }\end{array}$ & $\begin{array}{l}\text { Open surgery imposes greater } \\
\text { physical demand on the neck } \\
\text { muscles compared with } \\
\text { endovascular and laparoscopic } \\
\text { surgeries }\end{array}$ \\
\hline [42] & $\begin{array}{l}\text { 26: } 13 \text { with } \\
\text { training of the } \\
\text { non-dominant } \\
\text { upper extremity } \\
\text { and } 13 \text { without } \\
\text { training }\end{array}$ & Eye-hand coordination task & $\begin{array}{l}\text { EMG: Back, shoulder, } \\
\text { and forearm }\end{array}$ & $\begin{array}{l}\text { Training the non-dominant upper } \\
\text { extremity leads to better alternated } \\
\text { use of forearm muscles }\end{array}$ \\
\hline [43] & 100 & $\begin{array}{l}\text { Laparoscopic renal } \\
\text { procedures with and } \\
\text { without foot gel pad }\end{array}$ & Subjective criteria & $\begin{array}{l}\text { The use of foot gel pads improves } \\
\text { surgeon comfort and ergonomics } \\
\text { during laparoscopy }\end{array}$ \\
\hline [44] & 28 novices & $\begin{array}{l}\text { Nissen fundoplication } \\
\text { model }\end{array}$ & NASA-TLX & $\begin{array}{l}\text { Higher mental workload is } \\
\text { associated with poorer laparoscopic } \\
\text { performance }\end{array}$ \\
\hline
\end{tabular}

$N$ : Number of subjects or cases.

Table 1. Reported results for ergonomics in laparoscopic surgery. 
In a study with 30 surgeons with different experience in laparoscopic surgery, we analyzed the surgeon's muscle activity in back and forearm muscles during laparoscopic dissection and suturing tasks [29]. Percentage of the MVC of the trapezius, forearm flexors, and forearm extensors muscles was used for assessment of the muscle activity (Figure 6). Results showed that the surgeons with a higher degree of laparoscopic experience exhibited a lower level of muscle activity when compared with the novice surgeons. In another study with 50 surgeons, we analyzed the surgeons' hand spatial configuration during the use of two laparoscopic instrument handles, axial and ring-handled [11]. Movements of the surgeon's hand and wrist were recorded by a data glove and the level of wrist disorder was computed by a modified version of the RULA method [27] (Figure 6). Results showed that axial-handled needle holder entailed a more ergonomic posture for the wrist joint.

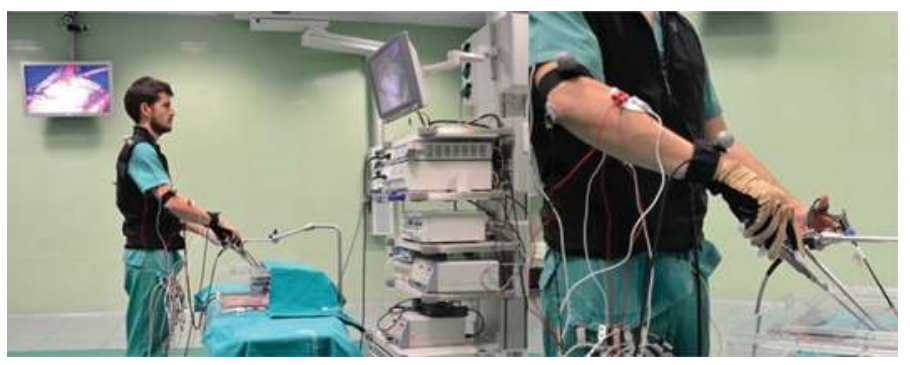

Figure 6. EMG and data glove data acquisition during the performance of laparoscopic tasks on simulator.

\section{New surgical approaches}

New surgical approaches have been presented to improve surgical outcomes and aesthetics results of patients. However, in some cases these surgical alternatives lead to an increase in technical and ergonomic challenges for surgeons that should be analyzed and identified.

\subsection{Laparoendoscopic single-site surgery (LESS)}

A summary of the results from the scientific literature for ergonomics in LESS are presented in Table 2.

In a study with experienced laparoscopic surgeons we assessed the surgeons' ergonomy during LESS, comparing it with conventional laparoscopic approach [5]. Surgeons performed a dissection tasks on a physical simulator using straight laparoscopic scissors and dissector for the conventional approach, and articulating tip scissors and dissector for the LESS approach (Figure 7). Ergonomic assessment was carried out by analyzing the muscular activity, and wrist and hand motion. Results showed that the LESS approach required greater level of muscular activity in the trapezius and forearm extensor muscles, but better wrist position compared with traditional laparoscopy. 


\begin{tabular}{|c|c|c|c|c|}
\hline Study & $N$ & Task & Assessment method & Results \\
\hline [34] & $\begin{array}{l}\text { 48: } 25 \text { with LESS } \\
\text { and } 23 \text { with } \\
\text { conventional } \\
\text { approach }\end{array}$ & Cholecystectomy & SURG-TLX & $\begin{array}{l}\text { LESS cholecystectomy is more } \\
\text { stressful and physically demanding } \\
\text { than the conventional approach }\end{array}$ \\
\hline [45] & $\begin{array}{l}24 \text { premedical } \\
\text { college students }\end{array}$ & $\begin{array}{l}\text { Peg-transfer with two } \\
\text { articulated and one } \\
\text { straight graspers }\end{array}$ & $\begin{array}{l}\text { EMG: Forearms. } \\
\text { Electrogoniometers: } \\
\text { Wrist. } \\
\text { SURG-TLX }\end{array}$ & $\begin{array}{l}\text { The straight instrument requires less } \\
\text { muscle activation and wrist deviation }\end{array}$ \\
\hline [46] & $\begin{array}{l}100 \text { procedures: } 50 \\
\text { triportal vs. } 50 \\
\text { uniportal }\end{array}$ & $\begin{array}{l}\text { Video-assisted thoracic } \\
\text { surgery }\end{array}$ & $\begin{array}{l}\text { Photogrammetry: Head } \\
\text { NASA-TLX }\end{array}$ & $\begin{array}{l}\text { Surgeons maintain a more neutral } \\
\text { body posture during uniportal VATS, } \\
\text { but with greater frustration }\end{array}$ \\
\hline [47] & 90 patients & $\begin{array}{l}\text { Laparoscopic pull- } \\
\text { through Soave } \\
\text { procedure: } \\
\text { conventional, LESS } \\
\text { and hybrid } \\
\text { approach }\end{array}$ & Subjective criteria & $\begin{array}{l}\text { The conventional and hybrid } \\
\text { approach have the same } \\
\text { maneuverability and are less } \\
\text { challenging than the LESS approach }\end{array}$ \\
\hline$[48]$ & 175 patients & $\begin{array}{l}\text { Different urological } \\
\text { procedures }\end{array}$ & Subjective criteria & $\begin{array}{l}\text { The use of conventional laparoscopic } \\
\text { instruments is ergonomically feasible } \\
\text { and safe in LESS procedures }\end{array}$ \\
\hline
\end{tabular}

$N$ : Number of subjects or cases.

Table 2. Reported results for ergonomics in LESS.

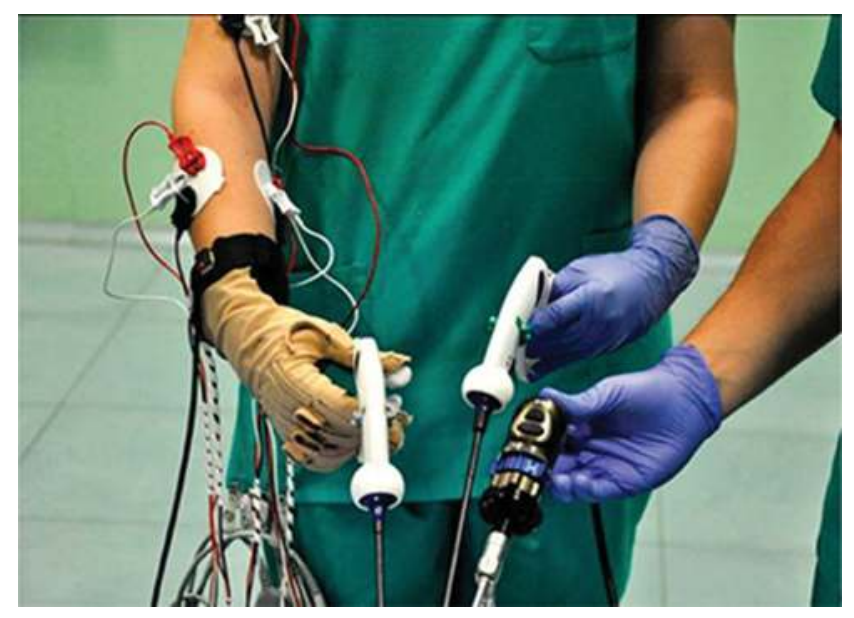

Figure 7. EMG and data glove data acquisition during the performance of hands-on simulator tasks using a LESS approach. 


\subsection{Robotic surgery}

Research has demonstrated the benefits of robotic surgery for the patient such as smaller incisions, reduced blood loss and postoperative pain, and reduced durations of in-patient care. Robotic platforms such as the da Vinci system (Intuitive Surgical Ltd., Sunnyvale, CA, USA) have been presented as a potential solution to the limited ergonomics in laparoscopic surgery.

In a study with surgeons with different levels of experience in robotic surgery, physical and cognitive ergonomic workloads using robotic-assisted and conventional laparoscopy were assessed during the performance of different basic laparoscopic training tasks [49]. Physical workload was assessed by using EMG from back, shoulder, arms, and forearms muscles, and mental workload by means of NASA-TLX index. They concluded that physical and cognitive ergonomics with robotic assistance were significantly less challenging. Another study comparing the use of standard laparoscopy and robotic assistance during intracorporeal suturing on porcine Nissen fundoplication models, medical students reported a lower workload using the robotic assistance [50]. Similarly, Moore et al. [51] reported significantly lower workload and mental effort on the robotic system compared to conventional laparoscopic approach while performing an eye-hand coordination task. Besides, another study using standard laparoscopic tasks during five consecutive training sessions, surgeons (novices and experienced) reported a less frustration score during and after training sessions and higher good mood score using robotic assistance [52]. The Imperial Test Assessment Tool was use to evaluate the frustration level.

\section{New surgical devices}

In order to overcome some of the ergonomic limitations of laparoscopic surgery, new surgical devices and instrument designs have been developed. In this section, we will review these novel surgical devices presented in the scientific literature. Studies published after 2010 and with no limit of subjects will be taken into account, excluding the review articles.

Several authors presented novel prototypes of ergonomically designed handles for laparoscopic instruments. One example is the Intuitool ${ }^{\circledR}$ laparoscopic instrument (University of Nebraska, Lincoln, NE, USA), which includes an ergonomic handle and a redesigned grasper actuation mechanism in order to create a more comfortable and intuitive handle-tool interface [53]. Büchel et al. [31] also presented a laparoscopic instrument prototype with an ergonomic pistol handle (Volargrip; University Hospital of Trondheim and Surgitech Norway AS, Trondheim, Norway). They compared this tool with two conventional laparoscopic instruments with ring handles. Results showed that each handle except the new prototype caused pressure areas and pain. A pistol grip laparoscopic instrument with a rotatable handle piece was presented by Steinhilber et al. [54]. EMG of the arm and shoulder muscles and wrist's posture by means of a gravimetric posture sensor were used to compare this novel instrument with the use of a conventional laparoscopic handle during the performance of a hand-eye coordination task. Results showed that the novel handle design did not decrease the biomechanical stress of the analyzed muscles, but neutral position of the wrist was more 
often. Yu et al. [55] compared a prototype laparoscopic grasper with three adjustable handle angles to a conventional instrument during the performance of Fundamentals of Laparoscopic Surgery tasks. Motion tracking and NASA-TLX were used to measure the surgeon's posture and workload. They concluded that the adjustable handle angle laparoscopic tool can reduce ergonomic risks of musculoskeletal strain and allows versatility for tasks alternating between positions.

Another possibility to improve the ergonomics in laparoscopy is by increasing the instrument's degrees of freedom. This is the case of the Radius Surgical System (Tuebingen Scientific Medical $\mathrm{GmbH}$, Tuebingen, Germany), which provides two additional degrees of freedom (deflection and rotation of the tip) and enables the surgeon to manipulate the instrument accurately and precisely in an ergonomic position [56]. This manipulator has been successfully used to treat cases of esophageal achalasia and gastroesophageal reflux disease [57].

Apart from laparoscopic surgical instruments, other support devices have been developed to improve the ergonomic conditions during surgery. This is the case of operating chairs [58] or arm supports [59], whose main objective is to improve the surgeon's ergonomic posture during surgery. A novel portable ergonomic simulator for training of basic laparoscopic skills was also presented by Xiao et al. [60].

\subsection{Handheld robotic instruments}

New handheld robotic systems have been developed for laparoscopic surgery and single-site surgery to deal with some of their technical and ergonomic limitations. They provide precisiondriven and articulating instrument tips, which increase the triangulation, and therefore improve the performance of some surgical maneuvers. One example of these systems is Jaimy ${ }^{\circledR}$ (Endocontrol, Grenoble, France), which provides two additional degrees of freedom controlled by a joystick placed on an ergonomic handle [8]. This handheld robotic instrument was ergonomically compared by means of surgeon's posture and muscular activity analysis with a conventional needle holder during the performance of basic laparoscopic training tasks. Results showed that the use of the robotized needle holder improved the surgeon's posture when compared to the traditional laparoscopic instrument.

The Kymerax ${ }^{\mathrm{TM}}$ (Terumo Europe NV, Leuven, Belgium) and DEX ${ }^{\mathrm{TM}}$ (Dextérité Surgical, Annecy, France) are other examples of handled robotic instruments for laparoscopic surgery and LESS. We have analyzed the ergonomics of these two surgical devices and compared it to conventional laparoscopic instruments by means of motion tracking, EMG of back, shoulder, and arm muscles, and data glove motion analysis (Figure 8). A positive learning curve in performance and ergonomics using the handheld robotic instruments has been reported. There were no differences in surgeon's muscle activity using the robotic and the conventional laparoscopic instruments, except for the biceps muscle. The robotic instruments led to an ergonomically more acceptable posture of the shoulder, elbow, and wrist. We believe that a period of adaptation should be required for this new technology. 


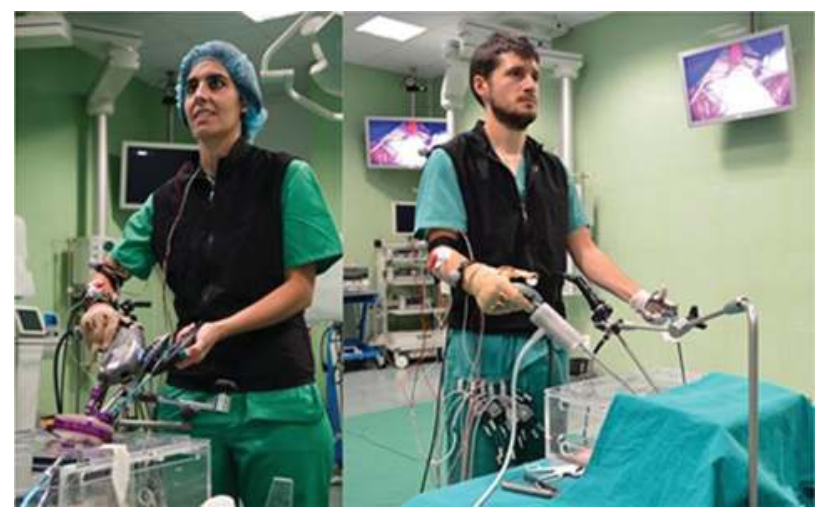

Figure 8. Setup for the ergonomic study in the training environment using (left) the Kymerax ${ }^{\mathrm{TM}}$ and (right) the DEX ${ }^{\mathrm{TM}}$ handheld robotic instruments.

\section{Conclusions}

Laparoscopic surgery entails a limited range of movements, which leads to acquire static, forced, and awkward long-term postures. The primary risk factor for the appearing of musculoskeletal disorders is body deviation from the neutral position. The ideal position for the laparoscopic surgeon is characterized by the arms slightly abducted, retroverted, and rotated inward at the shoulder level; the elbow should be bent at a $90-120^{\circ}$ angle; the hands should grasp the instruments with the wrist slightly extended. Results from the scientific literature showed that ergonomics during the laparoscopic surgical practice is related to the level of experience. Better ergonomic conditions during surgery lead to an improvement in task performance. Objective ergonomic analysis concluded that laparoscopic instruments with axial handel entail a more ergonomic posture for the wrist joint compared to a ring handle. Regarding ergonomics in LESS, studies reported that this surgical approach is more physically demanding than conventional and hybrid approaches. LESS approach requires greater level of muscular activity in the back and arm muscles, but leads to a better wrist position compared with traditional laparoscopy. Physical and cognitive ergonomics with robotic assistance were significantly less challenging when compared to conventional laparoscopic surgery. Further studies with a greater number of subjects should be done in order to obtain clear evidencebased findings of ergonomics during minimally invasive surgery.

\section{Acknowledgements}

This study was supported by the Government of Extremadura, Spain; the European Regional Development Fund (GR15175); and the European Social Fund (PO14034). 


\section{Author details}

Francisco M. Sánchez-Margallo ${ }^{1}$ and Juan A. Sánchez-Margallo²*

*Address all correspondence to: juan.sanchez.margallo@gmail.com

1 Jesús Usón Minimally Invasive Surgery Centre, Cáceres, Spain

2 Department of Computer Systems and Telematics Engineering, University of Extremadura, Badajoz, Spain

\section{References}

[1] Vereczkel A, Bupp H, Feussner H. Laparoscopic surgery and ergonomics-it's time to think on ourselves as well. Surg Endosc 2003; 17: 1680-2.

[2] Pérez-Duarte FJ, Sánchez-Margallo FM, Díaz-Güemes I, Sánchez-Hurtado MÁ, LucasHernández M, Usón J. Ergonomics in laparoscopic surgery and its importance in surgical training. Cir Esp 2012; 90: 284-91.

[3] Geng L, Sun C, Bai J. Single incision versus conventional laparoscopic cholecystectomy outcomes: a meta-analysis of randomized controlled trials. PLoS One 2013; 8(10): e76530.

[4] Matos-Azevedo AM, Díaz-Guëmes I, Pérez-Duarte FJ, Sánchez-Hurtado MÁ, SánchezMargallo FM. Comparison of single access devices during cut and suturing tasks on simulator. J Surg Res 2014; 192(2): 356-67.

[5] Pérez-Duarte FJ, Lucas-Hernández M, Matos-Azevedo A, Sánchez-Margallo JA, DíazGüemes I, Sánchez-Margallo FM. Objective analysis of surgeons' ergonomy during laparoendoscopic single-site surgery through the use of surface electromyography and a motion capture data glove. Surg Endosc 2014; 28: 1314-20.

[6] Koca D, Yıldız S, Soyupek F, Günyeli İ, Erdemoglu E, Soyupek S, et al. Physical and mental workload in single-incision laparoscopic surgery and conventional laparoscopy. Surg Innov 2015; 22(3): 294-302.

[7] Ficarra V, Novara G, Artibani W, Cestari A, Galfano A, Graefen M, et al. Retropubic, laparoscopic, and robot-assisted radical prostatectomy: a systematic review and cumulative analysis of comparative studies. Eur Urol 2009; 55: 1037-63.

[8] Bensignor T, Morel G, Reversat D, Fuks D, Gayet B. Evaluation of the effect of a laparoscopic robotized needle holder on ergonomics and skills. Surg Endosc 2016; 30: 446-54.

[9] Elhage O, Challacombe B, Shortland A, Dasgupta P. An assessment of the physical impact of complex surgical tasks on surgeon errors and discomfort: a comparison 
between robot-assisted, laparoscopic and open approaches. BJU Int 2015; 115(2): 274-81.

[10] Supe AN, Kulkarni GV, Supe PA. Ergonomics in laparoscopic surgery. J Min Access Surg 2010; 6: 31-6.

[11] Sánchez-Margallo FM, Pérez-Duarte FJ, Sánchez-Margallo JA, Lucas-Hernández M, Matos-Azevedo AM, Díaz-Güemes I. Application of a motion capture data glove for hand and wrist ergonomic analysis during laparoscopy. Minim Invasive Ther Allied Technol 2014; 23(6): 350-6.

[12] Rogers ML, Heath WB, Uy CC, Suresh S, Kaber DB. Effect of visual displays and locations on laparoscopic surgical training task. Appl Ergon 2012; 43: 762-7.

[13] Matern U, Waller P. Instruments for minimally invasive surgery. Principles of ergonomic handles. Surg Endosc 2009; 13: 174-82.

[14] Matern U. Ergonomic deficiencies in the operating room: examples from minimally invasive surgery. Work 2009; 32: 1-4.

[15] Gofrit ON, Mikahail AA, Zorn KC, Zagaja GP, Steinberg GD, Shalhav AL. Surgeons' perceptions and injuries during and after urologic laparoscopic surgery. Urology 2008; 71: 404-7.

[16] Xiao DJ, Jakimowicz JJ, Albayrak A, Goossens RHM. Ergonomic factors on task performance in laparoscopic surgery training. Appl Ergonom 2012; 43: 548-53.

[17] Van Det MJ, Meijerink WJHJ, Hoff C, Totté ER, Pierie JPEN. Optimal ergonomics for laparoscopic surgery in minimally invasive surgery suites: a review and guidelines. Surg Endosc 2009; 23: 1279-85.

[18] Berquer R, Smith WD, Davis S. An ergonomic study of the optimum operating table height for laparoscopic surgery. Surg Endosc 2002;16: 416-21.

[19] Van Veelen MA, Kazemier G, Koopman J, Goossens RH, Meijer DW. Assessment of the ergonomically optimal operating surface height for laparoscopic surgery. J Laparoendosc Adv Surg Technol A 2002; 12(1): 47-52.

[20] Berguer R. Ergonomics in laparoscopic surgery. In: Whelan RL, Fleshman JW, Fowler DL, editors. The SAGES Manual of Perioperative Care in Minimally Invasive Surgery. 2005. New York: Springer. pp. 454-64.

[21] Gianikellis K, Sánchez-Margallo FM, Skiadopoulos A, Sánchez-Margallo JA, Aranda JH de M. Head stabilization during minimal invasive surgery tasks: an uncontrolled manifold analysis. Procedia Manuf 2015; 3: 1434-41.

[22] Gianikellis K, Skiadopoulos A, Palma CE, Sanchez-Margallo FM, Carrasco JBP, Sanchez-Margallo JA. A method to assess upper-body postural variability in laparoscopic surgery. 5th IEEE RAS/EMBS International Conference on Biomedical Robotics and Biomechatronics, IEEE; 2014, pp. 76-81. 
[23] Lee G, Lee T, Dexter D, Klein R, Park A. Methodological infrastructure in surgical ergonomics: a review of tasks, models, and measurement systems. Surg Innov 2007; 14(3): 153-67.

[24] Youssef Y, Lee G, Godinez C, Sutton E, Klein R V., George IM, et al. Laparoscopic cholecystectomy poses physical injury risk to surgeons: analysis of hand technique and standing position. Surg Endosc 2011; 25: 2168-74.

[25] Jack D, Boian R, Merians AS, Tremaine M, Burdea GC, Adamovich SV, Recce M, Poizner H. Virtual reality-enhanced stroke rehabilitation. IEEE Trans Neural Syst Rehabil Eng 2001; 9(3): 308-18.

[26] Stalfors J, Kling-Petersen T, Rydmark M, Westin T. Haptic palpation of head and neck cancer patients-implication for education and telemedicine. Stud Health Technol Inform 2001; 81: 471-4.

[27] Sánchez-Margallo FM, Sánchez-Margallo JA, Pagador JB, Moyano JL, Moreno J, Usón J. Ergonomic assessment of hand movements in laparoscopic surgery using the CyberGlove. In: Miller K, Nielsen PMF, editors. Comput. Biomech. Med., New York, NY: Springer; 2010, pp. 121-8.

[28] Hermens HJ, Freriks B, Merletti R, Stegeman D, Blok J, Rau G, et al. SENIAM 8: European recommendation for surface electromyography. Enschede: Roessingh Research and Development. 1999.

[29] Pérez-Duarte FJ, Sánchez-Margallo FM, Martín-Portugués I, Sánchez-Hurtado MA, Lucas-Hernández M, Sánchez-Margallo JA, et al. Ergonomic analysis of muscle activity in the forearm and back muscles during laparoscopic surgery. Surg Laparosc Endosc Percutan Tech 2013; 23: 203-7.

[30] Szeto GPY, Ho P, Ting CW, Poon JTC, Tsang RCC, Cheng SWK. A study of surgeons' postural muscle activity during open, laparoscopic, and endovascular surgery. Surg Endosc 2010; 24: 1712-21.

[31] Büchel D, Mårvik R, Hallabrin B, Matern U. Ergonomics of disposable handles for minimally invasive surgery. Surg Endosc 2010; 24: 992-1004.

[32] Fan Y, Kong G, Meng Y, Tan S, Wei K, Zhang Q, et al. Comparative assessment of surgeons' task performance and surgical ergonomics associated with conventional and modified flank positions: a simulation study. Surg Endosc 2014; 28: 3249-56.

[33] Wilson MR, Poolton JM, Malhotra N, Ngo K, Bright E, Masters RSW. Development and validation of a surgical workload measure: the surgery task load index (SURG-TLX). World J Surg 2011; 35: 1961-9.

[34] Abdelrahman AM, Bingener J, Yu D, Lowndes BR, Mohamed A, McConico AL, et al. Impact of single-incision laparoscopic cholecystectomy (SILC) versus conventional laparoscopic cholecystectomy (CLC) procedures on surgeon stress and workload: a randomized controlled trial. Surg Endosc 2016; 30: 1205-11. 
[35] Hu JSL, Lu J, Tan WB, Lomanto D. Training improves laparoscopic tasks performance and decreases operator workload. Surg Endosc 2016; 30: 1742-6.

[36] Liang B, Qi L, Yang J, Cao Z, Zu X, Liu L, Wang L. Ergonomic status of laparoscopic urologic surgery: survey results from 241 urologic surgeons in china. PLoS One 2013; 8(7): e70423.

[37] Cass GK, Vyas S, Akande V. Prolonged laparoscopic surgery is associated with an increased risk of vertebral disc prolapse. J Obstet Gynaecol 2014; 34(1): 74-8.

[38] Franasiak J, Ko EM, Kidd J, Secord AA, Bell M, Boggess JF, Gehrig PA. Physical strain and urgent need for ergonomic training among gynecologic oncologists who perform minimally invasive surgery. Gynecol Oncol 2012; 126(3): 437-42.

[39] Sutton E, Irvin M, Zeigler C, Lee G, Park A. The ergonomics of women in surgery. Surg Endosc 2014; 28(4): 1051-5.

[40] Lucas-Hernández M, Pagador JB, Pérez-Duarte FJ, Castelló P, Sánchez-Margallo FM. Ergonomics problems due to the use and design of dissector and needle holder. Surg Laparosc Endosc Percutan Tech 2014; 24: e170-7.

[41] Filisetti C, Cho A, Riccipetitoni G, Saxena AK. Analysis of hand size and ergonomics of instruments in pediatric minimally invasive surgery. Surg Laparosc Endosc Percutan Tech 2015; 25(5): e159-62.

[42] Nieboer TE, Massa M, Weinans MJN, Vierhout ME, Kluivers KB, Stegeman DF. Does training of the nondominant upper extremity reduce the surgeon's muscular strain during laparoscopy?: Results from a randomized controlled trial. Surg Innov 2013; 20: 292-8.

[43] Haramis G, Rosales JC, Palacios JM, Okhunov Z, Mues AC, Lee D, et al. Prospective randomized evaluation of FOOT gel pads for operating room staff COMFORT during laparoscopic renal surgery. Urology 2010; 76: 1405-8.

[44] Yurko YY, Scerbo MW, Prabhu AS, Acker CE, Stefanidis D. Higher mental workload is associated with poorer laparoscopic performance as measured by the NASA-TLX tool. Simul Healthc 2010; 5(5): 267-71.

[45] Riggle JD, Miller EE, McCrory B, Meitl A, Lim E, Hallbeck MS, et al. Ergonomic comparison of laparoscopic hand instruments in a single site surgery simulator with novices. Minim Invasive Ther Allied Technol 2015; 24: 68-76.

[46] Bertolaccini L, Viti A, Terzi A. Ergon-trial: ergonomic evaluation of single-port access versus three-port access video-assisted thoracic surgery. Surg Endosc 2015; 29: 2934 40.

[47] Aubdoollah TH. Clinical outcomes and ergonomics analysis of three laparoscopic techniques for Hirschsprung's disease. World J Gastroenterol 2015; 21: 8903. 
[48] Tsai Y-C, Lin VC-H, Chung S-D, Ho C-H, Jaw F-S, Tai H-C. Ergonomic and geometric tricks of laparoendoscopic single-site surgery (LESS) by using conventional laparoscopic instruments. Surg Endosc 2012; 26: 2671-7.

[49] Lee GI, Lee MR, Clanton T, Clanton T, Sutton E, Park AE, et al. Comparative assessment of physical and cognitive ergonomics associated with robotic and traditional laparoscopic surgeries. Surg Endosc 2014; 28: 456-65.

[50] Stefanidis D, Wang F, Korndorffer JR, Dunne JB, Scott DJ. Robotic assistance improves intracorporeal suturing performance and safety in the operating room while decreasing operator workload. Surg Endosc 2010; 24: 377-82.

[51] Moore LJ, Wilson MR, McGrath JS, Waine E, Masters RSW, Vine SJ. Surgeons' display reduced mental effort and workload while performing robotically assisted surgical tasks, when compared to conventional laparoscopy. Surg Endosc 2015; 29: 2553-60.

[52] Passerotti CC, Franco F, Bissoli JCC, Tiseo B, Oliveira CM, Buchalla CAO, et al. Comparison of the learning curves and frustration level in performing laparoscopic and robotic training skills by experts and novices. Int Urol Nephrol 2015; 47: 1075-84.

[53] Rousek JB, Brown-Clerk B, Lowndes BR, Balogh BJ, Hallbeck MS. Optimizing integration of electrosurgical hand controls within a laparoscopic surgical tool. Minim Invasive Ther Allied Technol 2012; 21: 222-33.

[54] Steinhilber B, Seibt R, Reiff F, Rieger MA, Kraemer B, Rothmund R. Effect of a laparoscopic instrument with rotatable handle piece on biomechanical stress during laparoscopic procedures. Surg Endosc 2016; 30: 78-88.

[55] Yu D, Lowndes B, Morrow M, Kaufman K, Bingener J, Hallbeck S. Impact of novel shift handle laparoscopic tool on wrist ergonomics and task performance. Surg Endosc 2015. [Epub ahead of print].

[56] Di Lorenzo N, Camperchioli I, Gaspari AL. Radius surgical system and conventional laparoscopic instruments in abdominal surgery: application, learning curve and ergonomy. Surg Oncol 2007;16(Suppl 1): S69-72.

[57] Hirano Y, Inaki N, Ishikawa N, Watanabe G. Laparoscopic treatment for esophageal achalasia and gastro-esophago-reflex disease using radius surgical system. Indian J Surg 2013; 75: 160-2.

[58] Gözen AS, Tokas T, Tschada A, Jalal A, Klein J, Rassweiler J. Direct comparison of the different conventional laparoscopic positions with the ethos surgical platform in a laparoscopic pelvic surgery simulation setting. J Endourol 2015; 29: 95-9.

[59] Steinhilber B, Hoffmann S, Karlovic K, Pfeffer S, Maier T, Hallasheh O, et al. Development of an arm support system to improve ergonomics in laparoscopic surgery: study design and provisional results. Surg Endosc 2015; 29: 2851-8.

[60] Xiao D, Jakimowicz JJ, Albayrak A, Buzink SN, Botden SMBI, Goossens RHM. Face, content, and construct validity of a novel portable ergonomic simulator for basic laparoscopic skills. J Surg Educ 2014; 71: 65-72. 
